This item was submitted to Loughborough's Research Repository by the author.

Items in Figshare are protected by copyright, with all rights reserved, unless otherwise indicated.

\title{
The context and conservation of patent metamorphic furniture 1780-1820
}

\section{PLEASE CITE THE PUBLISHED VERSION}

http://www.iiconservation.org/node/2044

\section{PUBLISHER}

(c) International Institute for Conservation of Historic \& Artistic Works (IIC)

\section{VERSION}

AM (Accepted Manuscript)

\section{LICENCE}

CC BY-NC-ND 4.0

\section{REPOSITORY RECORD}

Edwards, Clive. 2019. "The Context and Conservation of Patent Metamorphic Furniture 1780-1820". figshare. https://hdl.handle.net/2134/9472. 
This item was submitted to Loughborough's Institutional Repository (https://dspace.lboro.ac.uk/) by the author and is made available under the following Creative Commons Licence conditions.

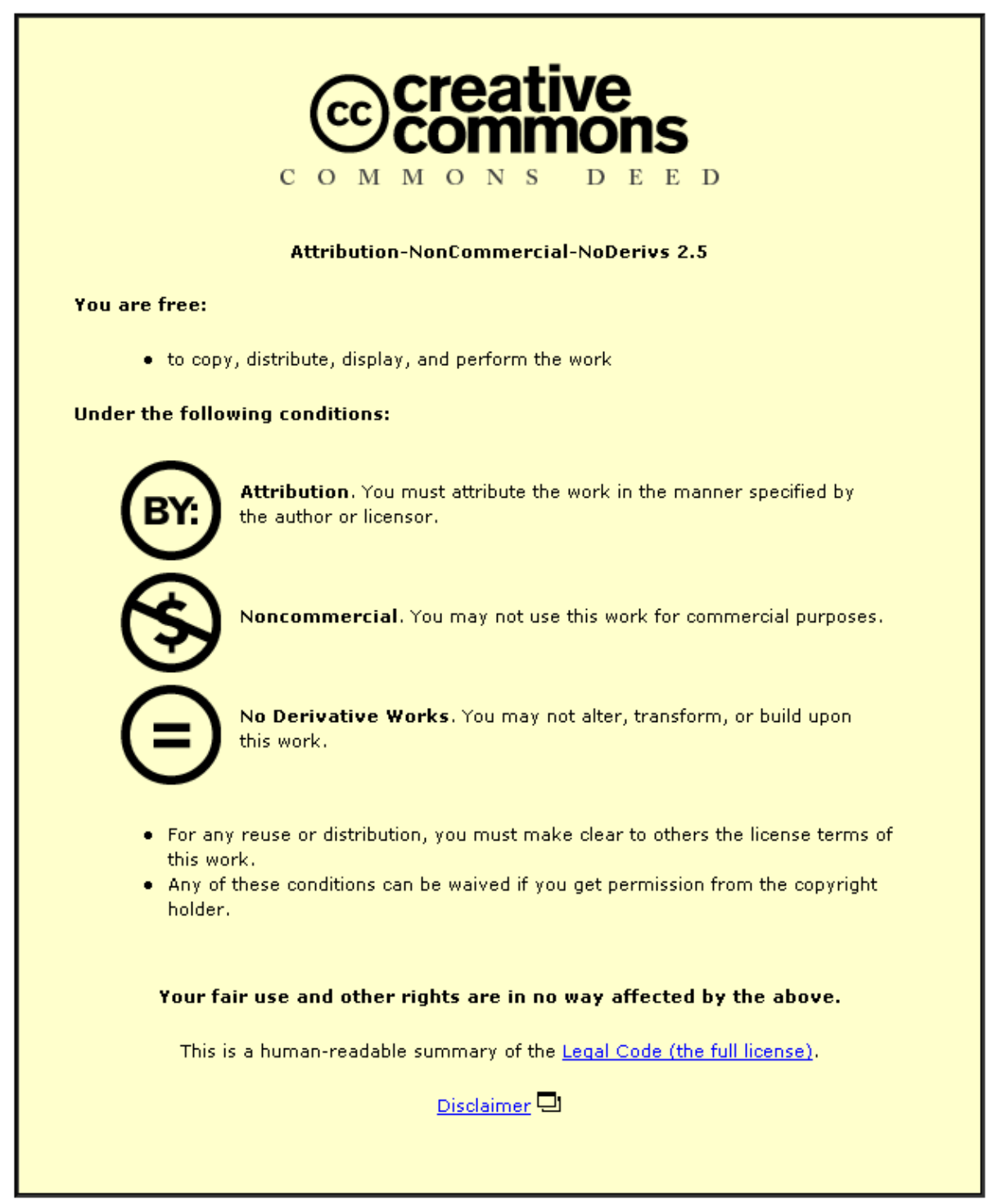

For the full text of this licence, please go to: http://creativecommons.org/licenses/by-nc-nd/2.5/ 
This paper addresses the role and nature of patents in considering the construction, use, social context and conservation issues of 'Metamorphic' furniture objects designed to be changed from one use to another or otherwise operated by moving parts. If part of the job of a conservator is to preserve knowledge as well as artefacts, then conservators need to draw upon as wide a range of documentation as possible in order to evaluate objects prior to assessment, treatment and interpretation. The patent documents often have drawings as well as specifications enrolled that can be very valuable in considering the furniture based on them. Patents often specified a new method of operating, locking or moving parts with a piece of furniture that was initially protected but was later used in a range of other models. Patents can therefore act as evidence of the intentions of the designer/maker and as templates for the original operation. An analysis of the context of making and usage (often in collaboration with colleagues from other disciplines) is also a major part of an understanding of products. Through a case study of the patents related to folding tables and associated products, links between meaning, making and conservation decisions will be made. In addition the study will demonstrate the value patents as a historical and contextual tool for conservators. This knowledge will go some way to ensuring accurate and ethically sound decisions are made concerning the object(s) under review.

'As it is the fashion of the present day, to resort to a number of contrivances for making one piece of furniture serve many purposes, ... it becomes necessary on this account as well as on many others, that the complete cabinet-maker should be acquainted with the principles of mechanics.' ${ }^{1}$ (Thomas Martin, Circle of the Mechanical Arts, 1813)

\section{INTRODUCTION}

The initial intentions and decisions of a conservator are based on a number of factors. Firstly a consideration as to why the object needs conserving, secondly finding out about the object and its 'values'. (As part of this contextualising process, the consideration of documents to understand the object, and the conservation issues that arise are important and valuable, as they often give insights into both making and meaning). Thirdly defining a treatment that is the best balance or compromise between the various and often conflicting demands. For example, the conflicts involving the roles of a museum object to educate its audience and the obligation to preserve the object for the future. On another level the issue of restoration versus conservation raises its head when the owner of the object intends to use it regularly. In this paper, I am assuming the objects will be for an institutional/ museum collection and not primarily intended for daily use.

These conflicts or compromises revolve around the varied and unbalanced requirements of the simultaneous need to reveal, investigate and preserve a particular object. In addition to these fundamental issues, a particularly thorny problem for conservators is dealing with 'mechanical objects' such as clocks, automata, and in this case, adjustable furniture. These object-types are subject to wear and tear and often the eventual failure of moving parts. The repair or replacement of moving parts is 
contentious. If an object cannot be interpreted unless it is operational, (i.e. astronomical clocks, mechanical toys) then there is an argument that the conservators' duty is to engage with that requirement and ensure the object is in working order. This of course raises its own set of problems with issues of repairing broken elements, the effects of carcase movements, the replacement of correctly fitting springs and weights and so on. Yet again another dilemma occurs when the 'historical continuity' issue emerges. To what extent do we repair or replace parts or modify the object to make it operational; any of which will alter the nature of the object. These decisions would have to be taken on a case-by-case basis.

To arrive at treatment decisions, particular conservation programmes should include consultation of all available documentation. In the case of patented objects, especially where the original workings are missing or restored inappropriately, the documentation is valuable for ascertaining the original intentions, as they usually included details of construction and assembly.

If preservation and elucidation of knowledge as well as artefacts is important to conservators, as I suggest it should be, patents are also useful for investigating the contexts of furniture history. These include the design of the objects; the manufacturing processes (often themselves subject to patent); the particular materials used, and the distribution and consumption of the objects produced. The subject of patents can also lead the cultural historian into wider areas of investigation. Patents are important because they reveal something more than a technological detail of a process or design. The sort of areas appropriate to furniture studies (apart from the obvious attribution of objects) could include an understanding of innovation and invention within and outside the trade; the use of illusion; attitudes to tradition and reform in furniture design, and the paradox of traditional designs using innovative processes and methods.

By considering the nature and role of patents, the demand and consumption of patent furniture, and the particular nature of metamorphic furniture through a case study, the value of patents to conservators as a research tool will be demonstrated.

\section{Figure 1 here}

\section{Patents and furniture [sub-heading]}

Before investigating the nature of patents and the metamorphic furniture associated with them, it is necessary to bear in mind three points that relate to working with this material. (Fig 1) The first is that not all patents granted were applied to actual products for sale and that those that were, may not have been successful in the marketplace. Of course, the granting of a patent and the subsequent production of the item is no guarantee of commercial gain or successful production. To explain why some patent furniture was extremely successful, whilst other ideas literally never got 'off the drawing board' is very complex. But at least part of the answer may be in attitudes to innovation. The purchasing public was: 'constrained by traditional conceptions of propriety and by definitions of what constitutes newness'. ${ }^{2}$ These boundaries of public acceptance are arbitrary but very real, so if an invention extends or falls short of the accepted boundaries of newness or propriety, it will fail

The second point is that the patentee would often sell or licence another party to exploit the patent for commercial use, therefore the maker might be different from the patentee. In a number of cases, the patentee is completely unconnected with the trade, although the evidence suggests that craftsmen took out the most successful patents. 
Thirdly, there were many innovations in furniture design and mechanics that never had patent protection. This was often because of the cost and time involved in the patenting process. The continuing advance of patents and inventions did not govern furniture trade practice in the same way as iron and steel or textile production might have been.

By analysing the number of patents granted during the period 1620-1885, it is possible to draw some conclusions about the patent system and its operation in relation to the furniture trade. ${ }^{3}$ A quantitative analysis reveals that the greatest number of patents granted relates to furniture castors, and bedsteads and upholstery stuffing materials follow this. These facts are not surprising and can be explained by the three main motivations behind patent furniture design: mobility, hygiene and comfort. Of true furniture patents, those that relate to chairs, both easy and folding, are the most numerous. This category is closely followed by folding bedsteads and invalid bedsteads and expanding dining tables.

There are two other forces in this analysis and they are not complementary. The first is the interest in the mechanics and variability of furniture that had been a feature of a number of later eighteenth/early nineteenth century cabinet-maker's works. ${ }^{4}$ Again, the novelty of innovative products has always been a selling point, particularly when the 'patent' label was appended to them. Often the furniture was required to have a dual purpose for reasons of space and economy, and this encouraged the inventive process. In most cases, the dual nature of the innovation was not prized simply for itself, but was seen as a necessity that had to be cloaked in a shroud of 'tasteful' clothing to make it acceptable. This was the metamorphic principle of objects appearing to be one shape or size, but actually concealing a novel mode of operation to convert their use. Therefore, innovative aspects of furniture design that were hidden behind conventional exteriors, suggest ambivalence towards change that explains why many patented inventions relating to furniture were attempting to replace older methods or materials without looking too new.

\section{Demand and consumption of patent furniture [sub-heading]}

The importance of the context of an item to be conserved has already been alluded to. This section therefore frames the type forms under review and demonstrates the value of cross-disciplinary studies.

An increase in demand for all types of furniture and furnishings was activated by a rapid population increase in the late eighteenth century onward. This growing market was to be satisfied in a number of particular ways by patent furniture. There were various demands made upon furniture for which 'patent' type objects were ideal. These included space saving, portability, hygiene and comfort.

In addition, there was a market for dual-purpose objects that was often related to the size of the family. A large family with a small number of bedrooms would need special arrangements for extra beds. Press beds or beds in cupboards had been in use for a long time. However, sensibility and social pressure suggested that 'a bed in a dining room is not nice'. The cabinet bedstead owned by David Garrick and supplied by Thomas Chippendale in 1768, (V and A; W.21-1917) is an illustrious example of a metamorphic item that lost its original function entirely during the nineteenth century by being converted into a wardrobe. Following the discovery and analysis of an inventory in 1970 it was discovered to have been a 'metamorphic' cabinet bedstead. The decision was later taken to remove overpainting to return the cabinet to its original colour scheme, but there was no move to replace any parts to try and return it 
to its 'original' condition. However, the value of the documentary evidence is clear. In any event, there may be an argument for demonstrating the intended operation of the piece by images, models or even reconstructions. ${ }^{5}$ For example, the documentation associated with the cabinet-maker Thomas Gale, who in 1772 invented a bedstead that when shut up resembled a bookcase or wardrobe. ${ }^{6}$ I will return to these issues in my case study below.

Whatever the camouflage, the notion of decorum, in which the alternative use of a piece of furniture is hidden, was part of a wider feeling that the specialised use of space, rational systems of storage and the careful planning of limited resources was both practically and morally superior.

The practical demands created by two medical issues also furthered the cause of patent furniture. The tolls of war and the subsequent need for invalid care, together with a strong desire to have hygienic beds were stimuli to inventions. One of the first concerns of patentees was to produce furniture that would relieve the suffering of patients, who were bedridden or incapable of self- propulsion. In the nineteenth century, the developments in invalid furniture were to influence designs for other forms of seating. In 1810, Parker and Cluley patented an adjustable bedstead, based on a frame with a fourfold motion. ${ }^{7}$ This principle was developed in 1813 , when Samuel James enrolled his patent for a 'machine for the ease of invalids or others'. (Fig. 2) This design was based on a Classical sofa shape but with a mechanism built in for adjusting the reclining or support of the occupant. ${ }^{8}$

\section{Figure 2 here}

It is clear from looking at the patent drawing that later in the object's life, it would have been a simple job to remove any malfunctioning parts and leave the sofa frame ready for upholstery for example, thus completely hiding the original use. Conversely if the example had some parts still extant it may be possible to demonstrate the operation of the sofa by repair or replacement of missing parts. Again the decision would depend on the perceived need, value of the object and the balancing of the client's requirements

By the end of the eighteenth century, there was a great demand for this sort of furniture, whether formally patented or not. For example, Thomas Sheraton produced a design for a ladies' writing table which had spring-loaded pen and ink drawers, a spring-weighted screen operated by lead weights and pulleys and also for a lady's dressing table with rising back mirror and side mirrors. The well known 'Harlequin' Pembroke table, so called because it used complicated mechanisms that were similarly employed in commedia dell'arte, was also illustrated by Sheraton. ${ }^{9}$

It is easy to see that over the course of time these mechanisms would fail and either be repaired locally, allowed to become inoperative or be removed completely.

Metamorphic furniture [sub-heading]

Convenience as well as comfort was a growing part of attitudes in eighteenth century interiors and their furnishing. To achieve this, many new furniture types were introduced, and a whole range of objects were produced which integrated different functions into one item. This sort of furniture design is perhaps indicative of how furniture-makers responded to the problem of a very varied range of demands. Some authors have suggested that the trend reflects a space-saving requirement that arose from a population increase and a demand for furniture convenient for use in crowded town dwellings. This, however, is only one side of the story. There was clearly a 
delight in metamorphic and dual-purpose furniture that was enjoyed by those with both large houses and small houses. Nevertheless, items that have modes of combining functions within one piece of furniture were often space-saving as well. This no doubt added to the convenience as well as to the amusement value of a piece.

One of the earliest examples was the well-known library steps contained in writing tables patented by London cabinet-maker Robert Campbell in 1774. ${ }^{10}$ The patent suggests that the principle could be applied to library tables, dining tables but also in card tables, breakfast tables, lady's dressing tables and other tables, chairs or stools. The enrolled patent drawing has eight figures showing the various permutations of application along with brief details of production. It is this idea of a principle being patented that is important and reminds us that there might be many versions of the same principle in a variety of furniture types. Clearly, the patent documentation would be important to conservators in ascertaining which particular arrangement was in front of them if presented with this object.

A most intriguing metamorphic furniture solution was devised by a London carpenter, Day Gunby in 1798. The patent was for 'Weights Bolts and Springs for Desks, Tables etc., 'intended to improve all kinds of writing and reading desks, tables, chairs, stools, tambour frames, library steps, bedsteads and various other articles'. ${ }^{11}$ (Fig. 3 and 4) This complex mechanism was explained in three pages of text and images to demonstrate the principles. For example, the writing desk was designed to include a rise and fall writing slope section and a similar rise and fall pigeonhole box that could be let down to be level with the table surface, all of which were operated by an arrangement of levers, springs, weights, pullies and wires.

\section{Figure 3 here}

Gunby specified that the operating cords could be of catgut (his preference), metallic chain or cord of hemp or hair, while the weights may be of iron, steel, brass, copper, or lead (his preference). Inevitably, through usage, these inner workings would begin to fail, and it seems likely that a number of carcases may exist today without their complete mechanisms. Gunby also shows drawings of the principle applied to tables and less likely, to armchairs.

\section{Figure 4 here}

In both cases, the principle of rise and fall was applied using triggers to release ratchets that allowed the rise and fall with or without weights. It is important to note that the London manufacturers, Seddon and Co., exploited Gunby's invention and some of these tables exist with a Seddon trade label but with no reference to the inventor.

These pieces (and those like them) are classic problem cases for conservators. If a dilapidated Gunby piece came to the workshop the conservator would be faced with a range of ethical questions. If it has been acquired as an example of metamorphic furniture, rather than a cabinet, then it would be logical to put it into working order, although this suggests some potentially intrusive actions. If the 'value' of the object is in its revealed history and function rather than its aesthetics, this course of action may be justified. Even this would not necessarily answer the need to 'reveal' the workings of a piece, which are often hidden. If intervention is not an option, then it may be possible to construct an open model of the workings that would demonstrate the systems used. This would have the added educational benefit of showing the hidden mechanism.

To consider these issues in more depth the following case study has been undertaken. 
Case study: Space saving dining tables [sub-heading]

The first patent with a specific space-saving intention was London cabinet-maker, George Eckhardt's portable table and portable chair of $1771 .{ }^{12}$ It was 'so contrived as to answer all the purposes of the common tables and chairs, and at the same time to lay in the compass of a small box'. The set was based on hinged components for both flaps and feet. An immediate problem in this case would possibly be the lack of the original box, which would have housed the demounted parts. As the interest is in the 'knockdown' construction, the conservator and client would have to consider how best to reveal this, without compromising conservation standards. Clearly it would be little point in simply displaying this object as a dining table.

The patent granted to carpenters, Richard Sweetman of Plymouth and Joseph Higgs of Westminster, in 1794, for 'improvements in the construction of tables' was the first of many versions of extending tables. ${ }^{13}$ The principle of this patent was that a double flap top would be able to flip over, swivel round and extend the table to twice its original size. The table also had a hollow-frame top that was designed to hold shaving, dressing or writing requisites. Both these patent tables had fairly simple actions that might be illustrated by showing a video of the operating process, thus explaining the workings most effectively, and thus avoiding the need to handle the object too much.

There was a veritable spate of patents for extending tables in the decade 18001810. No less than ten patents were granted for these versions of table opening and closings. Examples included tables that operated by the use of pulleys, endless chains and the well-known lazy tongs and screw motions. All this activity clearly reflects not only an interest from makers but also from consumers interested in this form of table.

In April 1800, London cabinet-maker John Marshall patented an 'improvement on tables'. His principle was based on a sliding frame within a frame that pulled out and had separate legs attached when extended. The extended frame also had hinged brackets on the ends of the frame to accommodate further leaves. ${ }^{14}$ This table though was essentially limited to one pedestal. In this case, missing legs might be a problem so their replacement would again depend on the final requirements of the owner. In this case, as the legs are integral to the operation and understanding of the mechanism a form or replacement would probably need to be supplied.

A month later on the $13^{\text {th }}$ May 1800, Richard Gillow, of the famous Lancaster and London Gillow company, designed an extending dining table which used wood or metal sliders to link together two or more table bases ready for insertion of extra flaps. His invention used 'wooden or metal sliders in dovetail, T or square, or cylindrical, or other grooves, with or without rollers', all being 'calculated to reduce the number of legs and pillars and claws of dining and other tables to facilitate enlargement and reduction of size'. ${ }^{15}$ In this case it may be justified to replace worn or damaged sliders as they are fundamental to the operation, and without which the table would be inoperable.

In 1802, London cabinet-maker Robert Walker patented an extendable table based on a pillar and claw design that in his example extended to 26 feet 9 inches. The patent was applicable to dining, loo, card, Pembroke and other tables, dumb waiters etc.. The distinction of Walker's invention was to 'remove the inconvenience of the claws [legs] that take up so much room, by the turning of the claws close together in the exact space of the diameter of the pillar, which in general is five inches, by an 
action of the brackets upon the claws, which, when turned out to support the flap the claw turns with it and when let down shuts back into its place... ${ }^{16}$ The swivelling brackets were linked to the claw legs by an iron rod fitted through the column, and when operated opened or close the claw leg like a lever. In all these examples, patent documentation should reveal construction details if repair or replacement is agreed, and will still offer contextual information if another conservation route is followed.

It is not surprising to find that one of the most well known patent furnituremakers and suppliers was involved in an extending-table patent. The London based cabinet-maker and upholster William Pocock was granted a patent for the 'improvement of dining tables and other uses which I term simpathitee' (sic) on 19th November 1805. (Fig. 5) This has later been referred to in the antique trade as a sympathetic table. The principle was based on a reciprocal action whereby pulling on a handle at one end of the table caused the frame to extend. This was achieved by a system of 'lines, chains and pullies and rollers, or cogs and wheels and racks and rollers'. ${ }^{17}$

\section{Figure 5 here}

Pocock ran a business in London specialising in patent furniture, so it is not surprising to see his advertisement include the 'sympathetic table' but also a further development of it (not patented) called a 'self acting table'. This allowed the two top leaves to be separated and an automatic placement of a third leaf to fill the space. A week later, on the $26^{\text {th }}$ November another patent for an extending table, but this time on a larger scale, was granted to London cabinet-maker Richard Brown. (Fig. 6) This patent was specifically applied to a range of furniture that could be 'disposed or folded up in a small space when not required to be used'. Moreover Brown explicitly states in the patent that 'the form and situation of the legs are susceptible of considerable variations, according to the uses and purposes to which the frames are to be applied, or the judgement of the maker, or the taste or choice of the buyer'. ${ }^{18}$ This is a fascinating sentence and again raises an issue for the conservator who in these cases may have to make a judgement (in conjunction with colleagues) as to an attribution and subsequent conservation. Brown's patent extension table was based on the concertina or 'lazy- tongs' principle with a cross rail and legs between each pair of tongs. Again, this was not exploited by the patentee but was successfully marketed by William Wilkinson \& Co. of Ludgate Hill.

\section{Figure 6 here}

In December 1807,London cabinet-maker, George Remington, invented a further 'improvement' on the extension of dining tables. This again consisted of a lazy-tongs motion that expanded tables in a concertina motion similar to Brown's patent of two years previously; however, this patent relied on a pair of legs being attached to each set of tongs. The improvement was on the fixing of the legs whereby they screwed into the hollow section of a hinge. It was apparently equally applicable to couches and chairs as to tables. The patent goes on to describe methods of supporting drapery around a chair, and then describes the construction of globe tables with locks and machinery. ${ }^{19}$ Remington's use of a relatively small detail of hinge construction highlights the necessity of close investigation of contextual documentation to reveal hidden detail.

\section{Figure 7 here}

Finally, this decade finished with the patent granted to London cabinet-maker Charles Stewart for more improvements in the construction of dining tables which folded 
down to make a console table. (Fig. 7) This was an interesting variation on the sliding loper design but allowed the top (which was hinged in two halves), to turn through 45 degrees using a quadrant action. Additional leaves could then be added as the sliders were pulled out of the frame. The frame included space to store leaves. ${ }^{20}$ This relatively straightforward arrangement has probably stood the test of time better than others.

William Doncaster patented one of the less well-known table extending devices, in 1814. Doncaster was not a cabinet-maker and this may be the reason for the eccentric nature of his patent. It was based on the principle of hydrostatic bellows that operated the rising and lowering of a rotary centre in a table. It seems highly improbable that it was ever made, although there may exist some remnant of the mechanism on a table somewhere. ${ }^{21}$ In any event, scrutiny of the patent drawings and specifications in conjunction with the object would clarify how it was to be used.

Further space-saving developments had to wait until the patent of Robert Jupe in 1835. Jupe's patent table was based on enlarging a dining table by the addition of segmental pieces. Jupe's patent specification again included a number of alternative designs for circular, oval, square and rectangular table shapes. He also showed two differing methods of enlarging the table frame. One was a straightforward pull-out mechanism based on sliding sections, the other was a more sophisticated arrangement which included a mechanical contrivance to swivel the sections out from the centre. ${ }^{22}$ This was one of the most successful patented tables, versions still being available some thirty years later.

These developments in patent furniture and the consequent innovations in material, process and technique were a distinct part of the furniture trade from the late eighteenth century. An understanding of patents and the products that were made under that label is clearly of benefit to conservators who wish to know their furniture from the inside out.

\section{Conclusion [sub-heading]}

As part of the conservation ethic is to preserve the social history of an object as much as the object itself, an understanding of patents as well as many other types of contextual material is essential in undertaking this task. This essay has demonstrated how contextual information, cross-disciplinary discussions and information exchange can be of real value to conservators who wish to reveal, investigate and preserve an object and understand something of the circumstances of its raison d'être. Whichever course of applied action is decided upon for a conservation programme for an object type, it's is clear that the patent information can be of assistance in revealing original intent, investigating the historical context, and aiding the conscientious preservation of the object.

\section{REFERENCES}

I am grateful to Paul Ellis, Sarah Gerrish and Paul Tear for discussions on this topic. ${ }^{23}$

1 Martin, T., Circle of the Mechanical Arts, London (1813) 110-11.

2 Barnett, H. G., Innovation: the Basis of Cultural Change, New York (1953) 9. 
3 See Van Dulken S., British Patents of Invention 1617-1977, A guide for

Researchers, British Library, London (1999). All patent references are to British Patents that are located in the Science Museum Library.

4 See for example, the work of J. J. Merlin, Catalogue of exhibition, 'J. J. Merlin, The Ingenious Mechanick', Kenwood, London (1985).

5 The V and A Museum (Conservation) website has a good example of this practice in the short video presentation on re-assembling the Melville Bed.

6 Thomas Gale, Patent No. 1002, 1772. For a more detailed examination of press beds see: Clive Edwards, 'Press Beds', Furniture History, 26 (1990).

7 Ebenezer Parker and Francis Cluly, Patent No 3387, 8 October 1810.

8 Samuel James, Patent No.3744, 1 November 1813.

9 Sheraton, T., Drawing Book, London (1893-4).

10 Robert Campbell, Patent No. 1086, 11 November 1774.

11 Day Gunby, Patent No. 2248, $6^{\text {th }}$ July 1798.

12 Anthony G. Eckhardt, Patent No. 995, 29 July 1771.

13 Richard Sweetman and Joseph Higgs, Patent No. 2007, 13 August 1794.

14 John Marshall, Patent No. 2393, $29^{\text {th }}$ April 1800.

15 Richard Gillow, Patent No. 2396, 1 May 1800.

16 Robert Walker, Patent No. 2657, $6^{\text {th }}$ November 1802.

17 William Pocock, Patent No. 2985, $19^{\text {th }}$ November 1805.

18 Richard Brown, Patent No. 2898, $26^{\text {th }}$ November 1805.

19 George Remington, Patent No. 3090, 16 December 1807.

20 Charles Stewart, Patent No. 3339, $22^{\text {nd }}$ May 1810.

21 William Doncaster, Patent No. $382726^{\text {th }}$ July 1814.

22 Robert Jupe, Patent No. 6788, 11 March 1835.

23 The $7^{\text {th }}$ International Symposium on Wood and Furniture Conservation,

"The Mechanics of Furniture" held at Stedelijk Museum Amsterdam, 26-7

November 2004 considered some of these issues.

\section{List of Figures}

Figure 1 Example of an English Patent 1798

Figure 2 Patent drawing from Samuel James's patent reclining sofa, 1813.

Figure 3 Detail drawing of Day Gunby's patent, 1798

Figure 4 Day Gunby's patent mechanism applied to a chair

Figure 5 Pocock's patent extending table 1805

Figure 6 Brown's patent table system 1805

Figure 7 Stewart's patent extending table 1810

\section{Biography}

Clive Edwards is Reader in Design History at Loughborough University. He has published widely in the field of furniture history and has a particular interest in the materials and techniques of furniture making, as well as the subsequent consumption 
of furniture. He was a contributor to Rivers and Umney, Conservation of Furniture (2003). His most recent major publications are Encyclopaedia of Furniture-Making Materials Trades and Techniques (Ashgate, 2000) and Turning Houses into Homes (Ashgate, 2005).

Address: School of Art and Design, Loughborough University, Loughborough, Leicestershire, LE11 3TU.

E-mail: c.edwards@lboro.ac.uk 